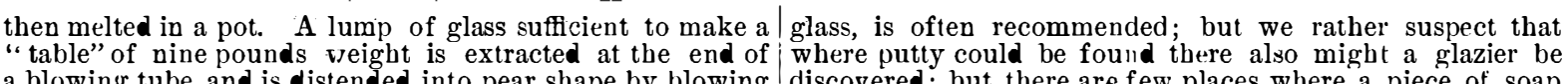
\begin{tabular}{l|l} 
"table" of nine pounds veight is extracted at the end of & where putty could be fould there also might a glazier be \\
a blowing tube, and is distended into pear sbape by blowing & discovered; but there are few places where a piece of soap \\
through the tube and rolling on the marver, which is a cast- & could not be obtained; and a piece moistened and rubbed over
\end{tabular} iron slab on a stand. Being softened by heat at the mouth of a small blowing furnace, it is rolled on the marver and
blown till it assumes a more spherical shape, but has a conblown till it assumes a more spherical shape, but has a con- a time for the purposes we are discusing; but, though better
ical end, which is removed as the glass approximates a than nothing at all, it forms but a poor substitute, owing
spherical form, being blown as it is rolled on the bulliou bar. to its opacity, compared with the other methods we bave spherical. It is then presented at a larger furnace bole called A pontil tipped with molten glass is then applied to the
center of the flat portion, and the blowing tube is detached by touching the neck of the globe with a cold, wet iron. was detached. Heat and rotation being still applied, first at a furnace opening of moderate size called the nose-bole, and
then at a much larger one called a flashing-furnace, the hole becomes more and more enlarged as the article becomes more and more oblate. Finally it flies open with a sharp rustling noise, and appears as a flat plate, called a "table," adhering at
its central thicker portion, the bull's eye, to the pontil, by
which, during the latter portions of the process, it was rested which, during the latter portions of the process, it was rested on the book in the balf-wall before the furnace, which formed
When it has cooled sufficiently to be rigid and not liable When it has cooled sufficiently to be rigid and not liable
to bend or collapse, it is placed on a fork, the pontil detacbed by the application of a cold iron, and the "table" placed in haps twenty-four hours, gradually cooling. The annealing arcb is termed a lear, and this is often made continuous; the are, receive carried along as the trays of recently made glass are received at one end, while the contents of the trays at the
discbarge end, having cooled sufficiently to bear bandling, The size of a " table " or disk of crown glass is about fiftytwo incbes, and a pot bolding one-balf ton will make abou
100 " tables."-Glassware Reporter.

SUBSTITUTES FOR GROUND GLASS

MANY occasions for the use of obscured glass might arise
when the expense of a special piece would not be justified when the expense of a special piece would not be justified; pose, or on a large scale, when fineness of surface was not rendering an ordinary sheet of glass suitable for the purpose will be very useful.

The simplest and most efficient plan is to varnish it with a
special varnish which will dry with a matte surface. There several such to be found in commerce; but, as they are not very difficult to make, we give two formulæ, both of which matte without the application of heat.
No. 1 is mede by preparing the two following solutions separately and then mixing them together, the mixture being

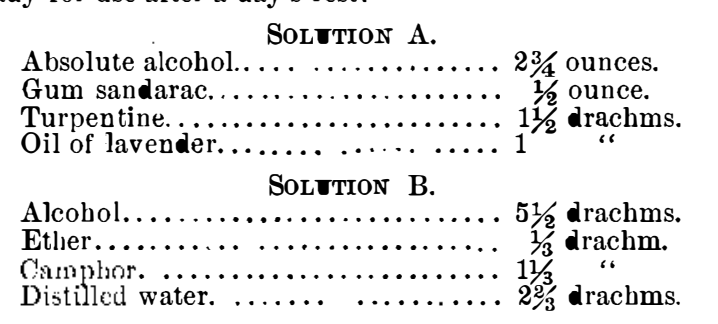

No. 2 is a simpler form, and we believe answers as well

if not better than, the more complex one just given :

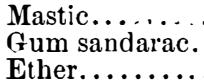
$51 / 2$ ounce.

Powder the gums and add to the ether, and shake till dis
lved: then filter or pour off from the sediment after stand solved: then filter or pour off from the sediment after stand-
ing a while, and add of benzole from two to two and three-
quarter ounces, beginning with the smaller quantity and quarter ounces, beginning with the smaller quantity an
testing till a surface of the right degree of fineness is pro-
duced upon evaporation. The bottle containing this sol duced upon evaporation. The bottle containing this solu-
tion requires to be exceedingly well corked, or the contents tion requires to be exceedingly well corked, or the contents dry with a coarse grain, the exact proportion of the solvents $\mathrm{f} \mathrm{sT}$ - dilution not being readily hit upon.
For purposes where a surface of the most extreme delicacy is required, we bave it on the autborit y of a very eminent
optician thit a solution of gutta-percla in chloroform surpasses every thing else. It would be rather an expensive var-
nish, and one to be carefully used; but if the eulogiums benish, and one to be carefully used; but if the eulogiums be-
stowed upon it be justified, there can be no doubt of its extreme usefulness in some cases.
Another easily applied coating is a thin starcb-arrowroot, corn flour, etc. - solution, which when dry leaves a very fair mentioned ingredients are at hand it affords a substitute by mentioned ingredients are at hand it affords a substitute by varnish thinned with spirit and applied cold.
Mr. W. B. Woordbury some little time ago published a simple but most effective metbod of producing a dead white,
opal-like coating upon glass. It consisted of mixing together opal-like coating upon glass. It consisted of mixing together surface of the glass. This impression is tben covered with
ordinary negative varnish and uniodized collodion, and a thin coating of gold, which acts as a powerful conductor
pouring the mixture cold upon the glass. When dry, the of copper, and the glass is now placed in a galvanic bath, result is a beautifully-matte white surface, very solid and : where the copper is gradually deposited over the whole of the opaque-looking. Upon trying it for the irrst time, it struck plate. When the deposited copper has attained a sufficient as as being the very thing for a simply made substitute for thickness, it is taken from the bath, and the glass is re
ground glass; but, to our disappointment, it did not approach moved. We then lave a copper plate with the picture cut
the benzole and etber formula (No. 2) as above. It required upon its surface, exactly corresponding to the carbon print; the benzole and etber formula (No. 2) as above. It required a considerable amount of dilution to make it in any way
transparent ennugb, and when so altered it was too irregular transparent ennugh, and when so altered it was too irregula
and coarse-grained to be of use for any but rough work.
Not to make our remarks extend to too great a length. w will conclude our review of methods by alluding to those the engraver. According to the character of the original, it ixtemporized plans needed to remedy some disaster or acci : partakes of the nature either of an engraving in line, or of a
dent; as, for instance, when a foot is put through a focus- : mezzotint engraving, and it is this quality of mezzotint suring-screen; or when, at the end of a long journey and far away from all glaziers, it is found that some extra severe
concussion has broken the glass to pieces. To indicate any concussion has broken the glass to pieces. To indicate any. which be bad to contend was to give such a surface as
of the virtues of one varnish over anotber at sucb times, or would bold the ink. and this he bas now accomplished in a
of the need for a specially prepared obscured glass, would very remirkable degree. A certain amount of hand work
only be to increase the weight of the tourist's sorrow. We must imagine that in the majority of cases the supplying of a piece of the photograph, which sometimes gives und ue force to
of glass to size would be the most serious difficulty; but, the delicate portions of the original drawing; but, broadly bat being overcome, it is a sliglt matter so to prepare the that being overcome, it is a slight matter so to prepare the speaking, the process is purely and wholly mechanical, and
plass as to make it answer all practical purposes as a stop. the copper-plate, as we have seen, is absolutely grown upon
crap. Putty, used as a dabber over the whole surface of the the raised print.

IMPROVED METHOD OF PHOTO ENGRAVING.

In a recent lecture by J. Comyns Carr. the following "Mr. Dawson makes no great secret of the principle on explain to you the ingenious mode in which admirable re-
ults are obtained. You will observe, in the first place, tbat same manner, and by the same press, as a copper or steel engraving; but instead of the picture being engraved upon
the plate, as one migbt expect, the plates are themselves, so
to speak, produced upon the picture. It is the picture in
Ir. Dawson's process which really creates the plate; and the Mr. Dawson's process which really creates the plate; and the
way in which this is accomplished is so remarkable that perhaps you will allow me to give a few words of explana-
ion. The first thing that Mr. Dawson does, after having photographed his subject, is to take from his negative
carbon print; 1 bis print is taken, not on paper, but on glass and as the principle of a carbon print consists in the deposit solid pigment, the picture so taken upon the glass repr fents a very delicate work in relief; that is to say, the surthat is to say, those portions which in the print were in re
lief are now in intaglio, and every delicate gradation is ex the present time in all its bearings; but the recent experi-
ments of Scbumann not only serve to throw some new ligbt
n the matter, but will doubtless lead to a further and closer made acid, i and \section{in in}

"There is scarcely any kind of original work to whicb this process may not be applied with success. In the reproduc. tion of a drawing in pen and ink, the result resembles a
strongly bitten etching. It is equally successful in imitat-
ing the effect of a drawing washed with a brush, or of a ing the effect of a drawing wasbed witb a brusb, or of a
drawing in chalk; but as deposited copper is al ways more
or less soft in substance, the plate, before it is 1 set by the printer, is covered with a thin film of steel, and we bave which any number of impressions can be taken; for so soon
as this thin film of steel sbows signs of wear, the printer as this thin film of steel sbows signs of wear, the printer
stops his labor, and the steeling is renewed. This process of stops his labor, and the steeling is renewe
steeling a plate is now verr generally applied to engraved
work on copper, and its effect is practically to abolish the distinction which once existed between proofs and prints.
The value of a proof in former times consisted in the fact that it ave an impression of the plate in its full strength, before it had become worn by successive printings; but now which can be taken from the steel plate, nor is there, as is sometimes supposed, any loss of the most delical
ship by the process of steeling."-Photo. Neros.

SIMPLE METHOD OF MIXING SOLUTIONS FOR ALKALINE PYROGALLIC DEVELOPMENT OF GELATINE PLATES.

\section{By J. KAY.}

I TAKE a bottle of pyrogallic containing one ounce of the ncentrated solution, and may be labeled "Stock Solution,"
d one, I find, that keeps much better than a solution I d for many months, whicb was made the yroper strength
the first instance. For ordinary use I take 2 drams of stock solution and dilute with 6 drams of methylated spirit,
and keep in a wide moutb 3 -ounce stoppered bottle. I find 1 ounce of this quite sufficient to bave mixed at a time. I Pyrogallic acid .....
Metbylated spirit

1 ounce.

rather, it would read thus if the whole bulk were so mixed.

If about to develop a balf plate, I take $\frac{1}{4}$ ram of this di-
ute solution and put into an ounce measure; or, ratber, I lute solution and put into an ounce measure; or, ratber, I
bave a $\neq$ dram marked on my ounce measure, and pour the
pyrogallic direct in, as pouring a $\frac{1}{4}$ dram from one measure pyrogallic direct in, as pouring a dram from one measure
to anotber would not be a very profitable proceeding; I then
add common water to make up 6 drams. The reason I use so small a quantity as $\frac{1}{4}$ ram of pyrogallic solution is, that
it is advisable, in saving time and water, to employ as small a quantity of spirit as possible. The strength of this pyro-
gallic solution when diluted with water as above mentioned gallic solution when diluted with water as above mentioned
is $2 \frac{2}{3}$ grammes to the ounce, which I find to be very suitable Common water $\ldots \ldots \ldots \ldots \ldots \ldots \ldots$ ounces

drams of this solution added to 6 drams of the pyrogallic
olution is ample for developing a balf plate. I would solution is ample for developing a balf plate. I would strongly insist upon using a good proportion of bromide in
the developer. It is a good preventive of green fog, besides giving clearness to the shado $\vec{w} s$ of the picture and brilliancy to the negative. In cases where plates bave a decided ten-
dency to fog, I use double the amount already stated. I am af bromide, but with me rapidity is only a means to an end. fof bromide, but with me rapidity is only a means to an end. PHOTOGRAPHIC PAINT FOR MACHINERY.

IT is a difficult matter to photograph a machine smootbly and effectivelv, and little success is likely to ensue unless
the whole is first covered with a gray paint or wash. The Photo. Newos says that one of thebest in use by photograph-

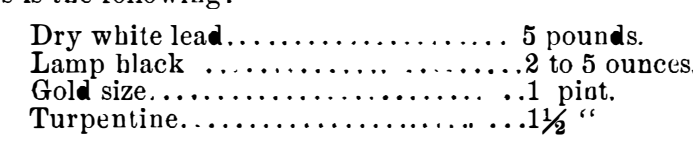

The amount of lamp black is varied according as a ligbt Tre amount of lamp or dark gray is best suited to the macline or the
ligbting. The paint is quite barmless, and is easily removed witb turpentine rubbed on witb a handful of cotton waste. THE APPLICATION OF ELECTRICITY TO SHIPS' LOGS.

THEse are days of rapid scientific progress, and the great
terest so recently excited by the application of electricity, in a new and startling way, to transmit information, bas
been almost eclipsed by the attention which its use for been almost eclipsed the attention which its use for
lighting and the transmission of power has attracted.
Though no longer confined to signaling, yet this is stlll its Though no longer confined to signaling, yet this is stlll its
most important use, and one for which its employment is being extended in many directions, always with the most
satisfactory results. It is with the application of electricity, satisfactory results. It is with the application of electricity,
this fleet messenger, for giving a constant record of the rate of a ship that this article is concerned. Before, bowever, about logs generally. Ordinary ships' logs are of two kinds, called respectiveiy
harpoon and taff rail logs. Harpoon logs, which are the
most extensively used, consist of a cylinder, on one end of most extensively used, consist of a cylinder, on one end of
which works a fan or screw, registering the number of revoutions by means of clockwork within the cylinder, the dial
being visible through a glass face. To the other end, which being visible through a glass face. To the otber end, which tached "log, the revolving fan and case for the clockwork being two separate pieces. To both these los there are
several objections, such as the almost unavoidable entrance of salt water to tbe wheelwork, the drag on the ship, which is often as much as $40 \mathrm{lb}$. or more, the inconvenience of the loss of the whole instrumert, sbould the towing line
break. To obviate these objections, the taffrail log was invented,
and which gnes a step further than the detarbed log, by and which goes a step further than the detarbed log, by
taking away the recording portion to the taff rail of the ship, and causing the towing rope to transmit the revolutions of
the fan to it. These logs are, in nany respects, a great im provement on the first; the egistering dial is less liable to 